兗㝝日五十二月一十年二十三治明

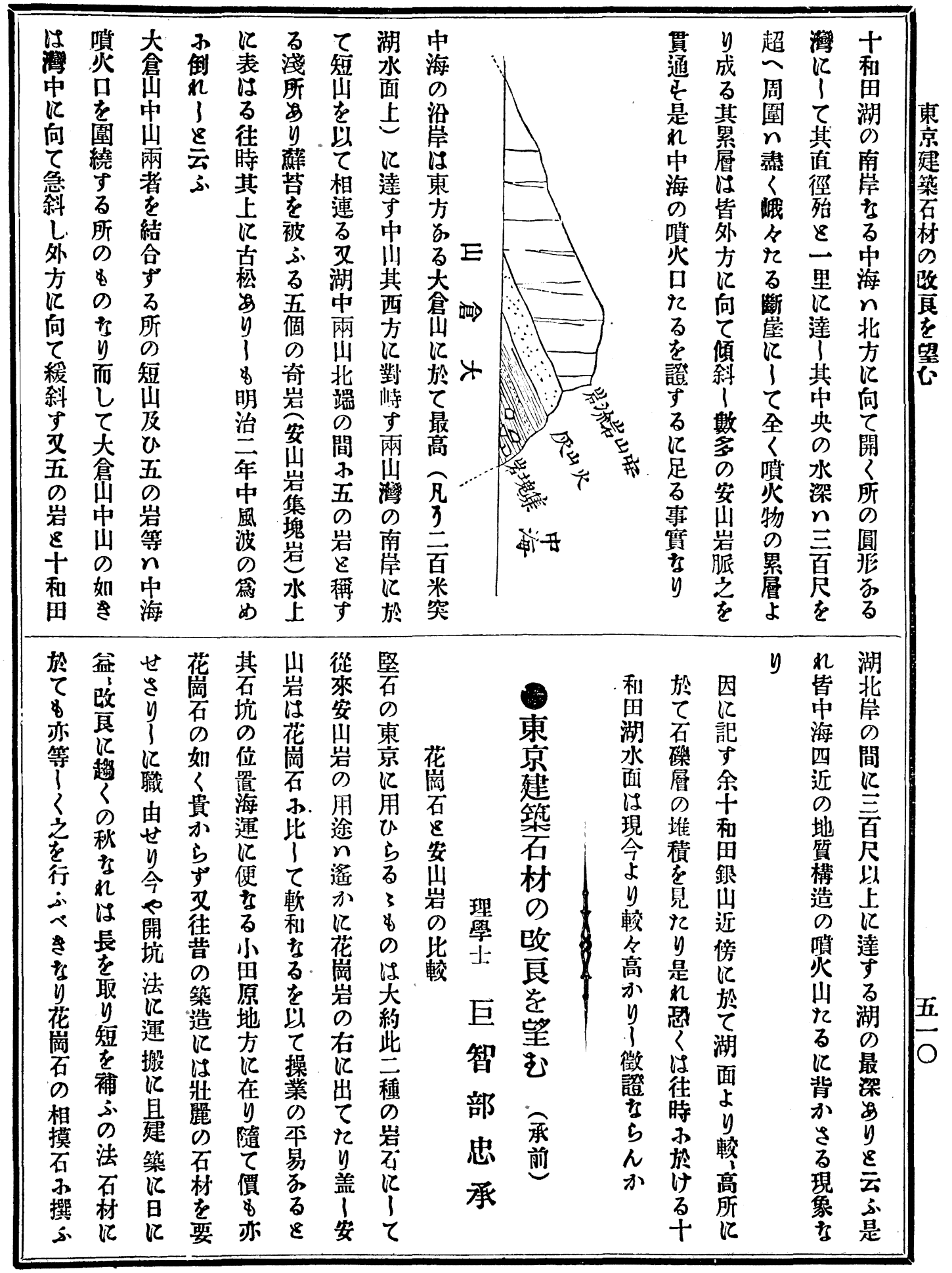


卷一十第集一第誌雑學地

\begin{tabular}{|c|c|c|c|c|c|c|c|c|c|c|c|c|c|c|c|c|}
\hline 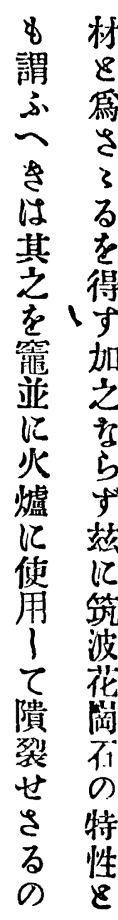 & 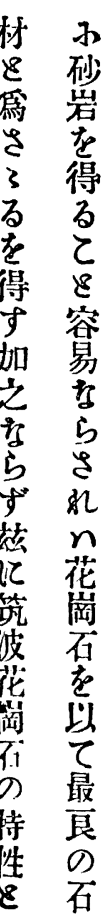 & 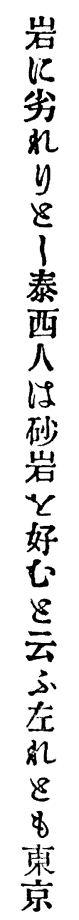 & 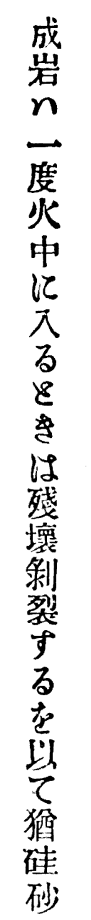 & 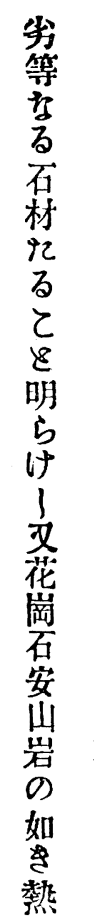 & 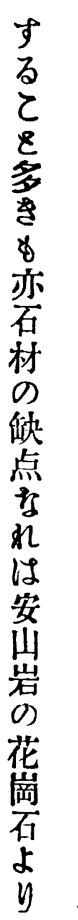 & 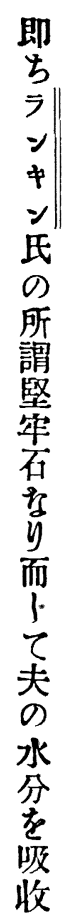 & 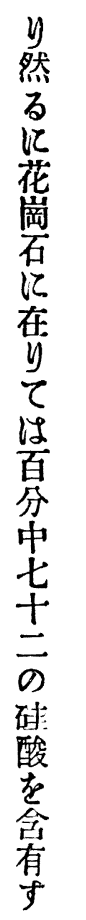 & 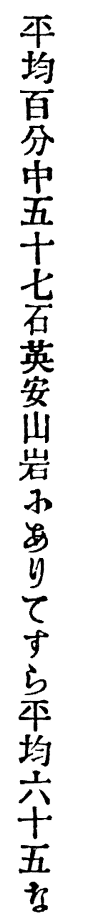 & 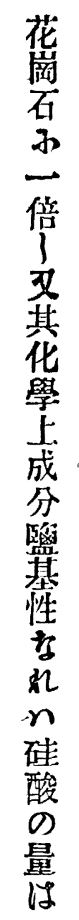 & 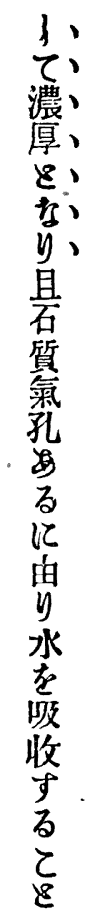 & 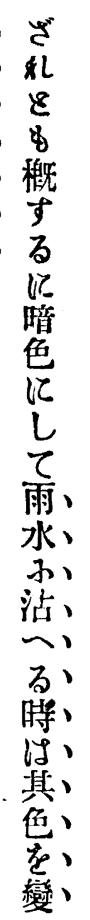 & 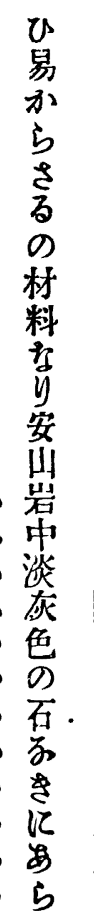 & 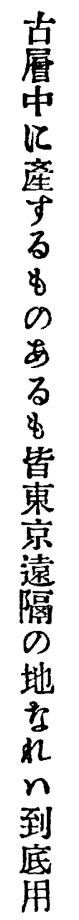 & 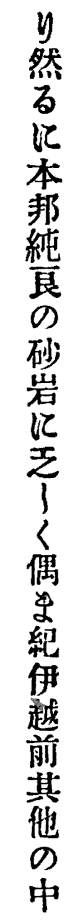 & 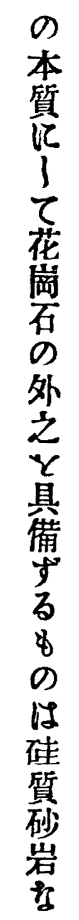 & 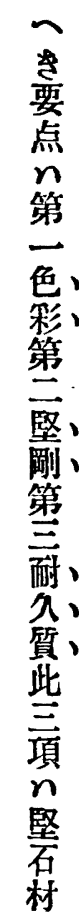 \\
\hline 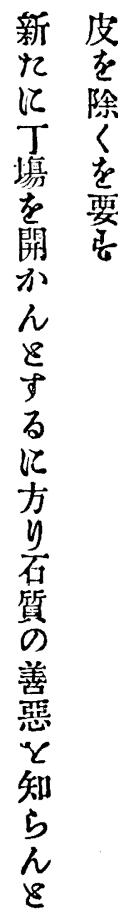 & 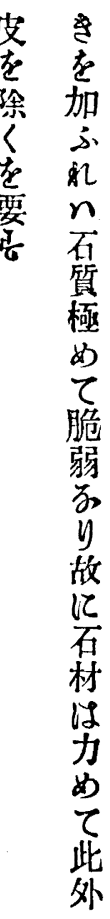 & 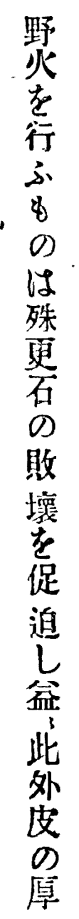 & 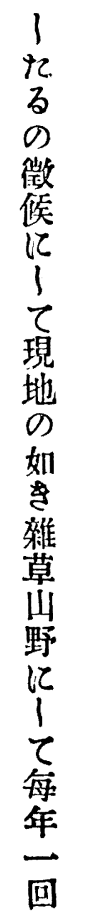 & 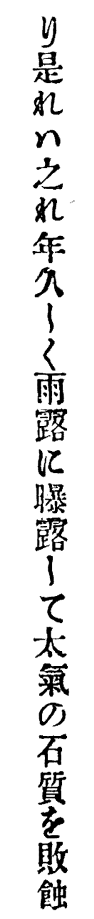 & 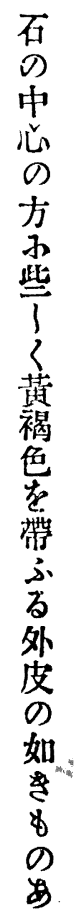 & 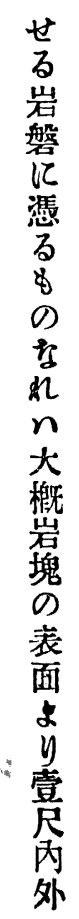 & 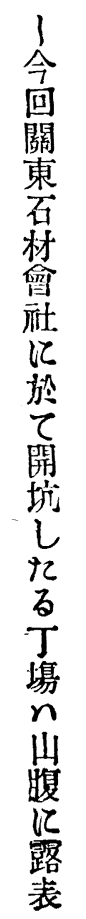 & 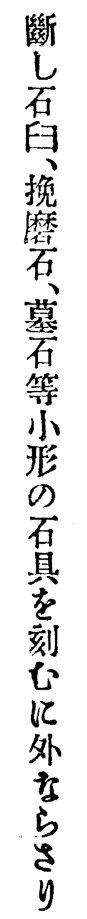 & 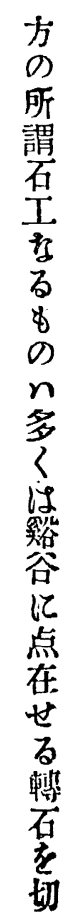 & 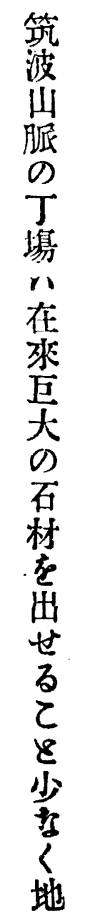 & 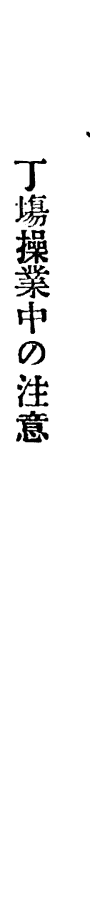 & $\begin{array}{c}3 \\
\frac{3}{3} \\
1 \\
1\end{array}$ & 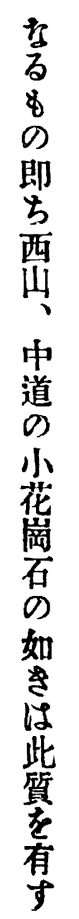 & 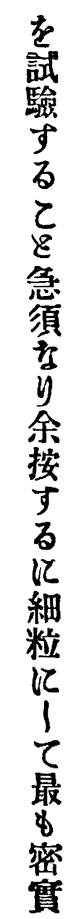 & 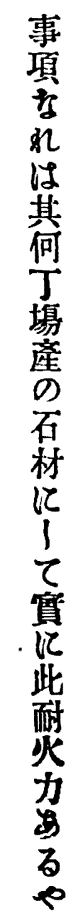 & 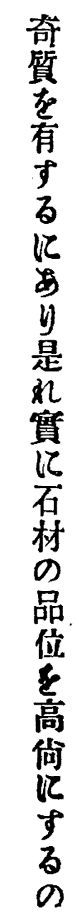 \\
\hline
\end{tabular}


召繁日五十二月一十年二十二治明

寸目了若にの永坑

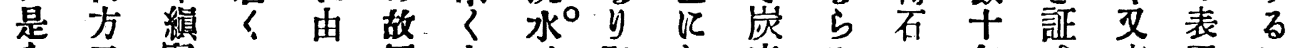

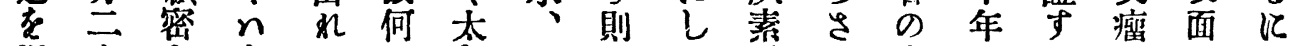

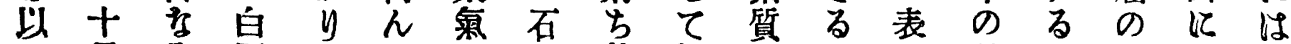

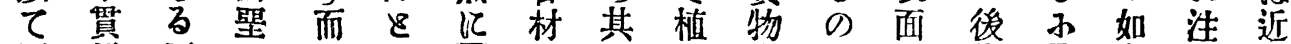
石自石のし咅露忏啠物在故黑復足き意傍

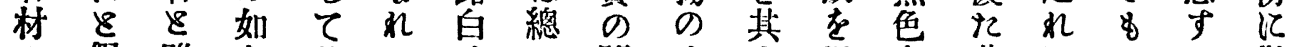

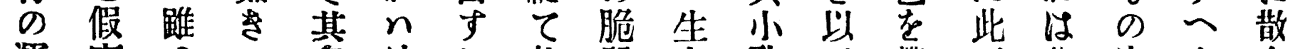

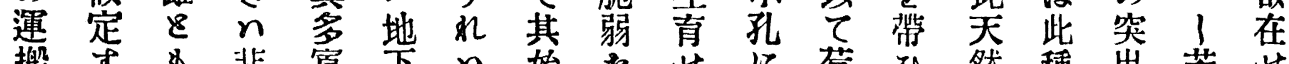
搬与非頞下 $n$ 始势世落ひ然種出若世

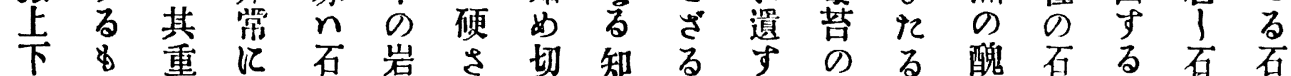
に三量多の石者鸟当8 \& 之

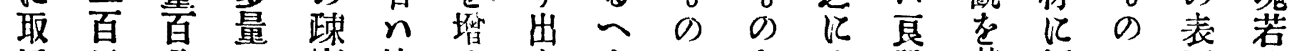

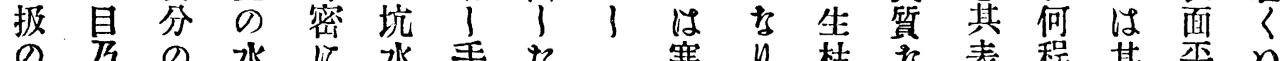

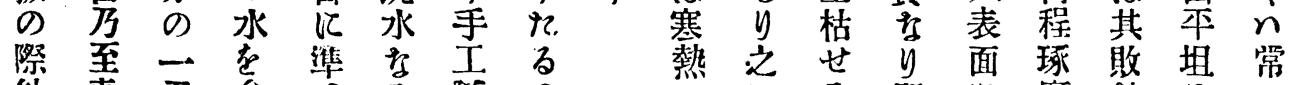

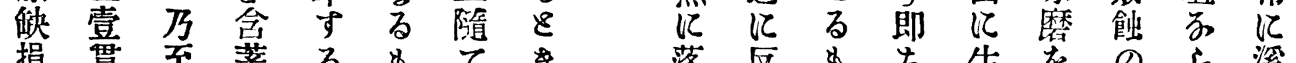

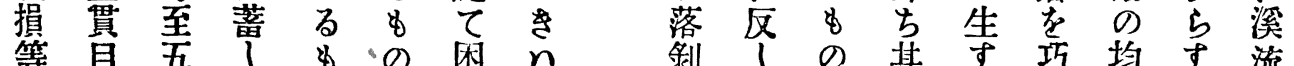

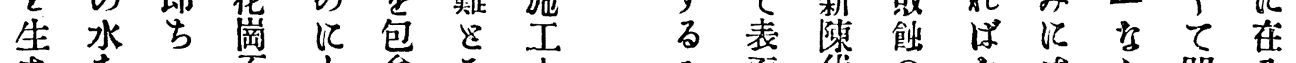

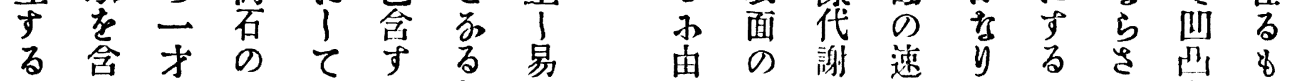

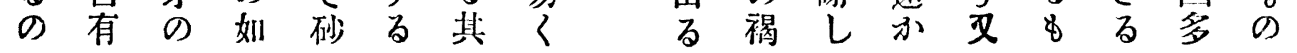

てには籍各經粗練か＼cjkstart吸蒙石

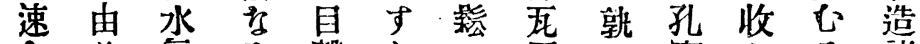

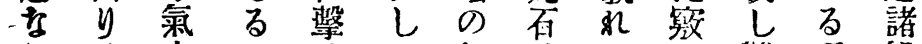
分中 分吉 $\tau$ 伊造 几子にみる 既豆

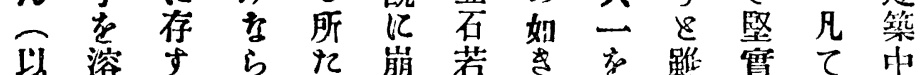

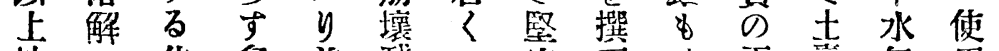

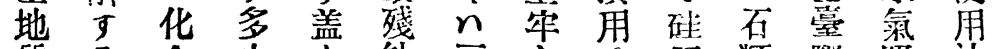
質白合少了嗮房吉吉石類際吸法 要と物 9 此 $の$ 州要る質が散

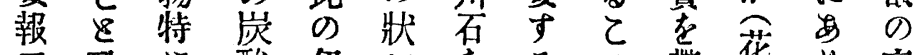

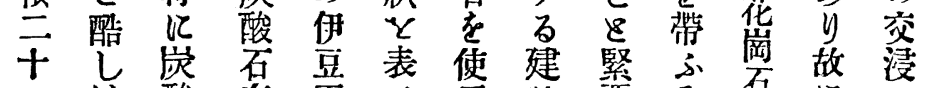

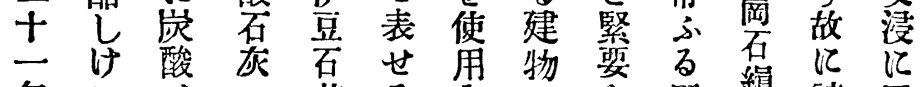

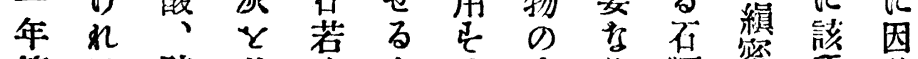

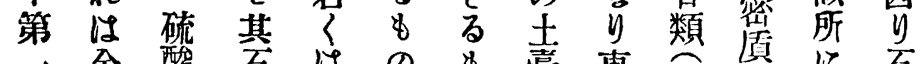

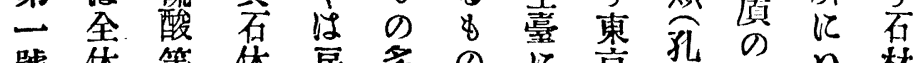

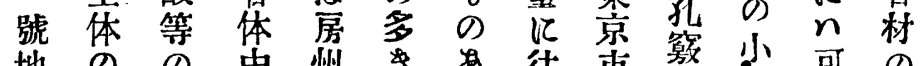

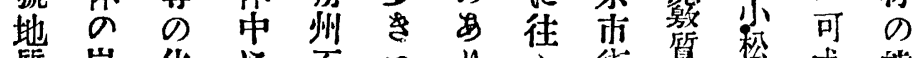

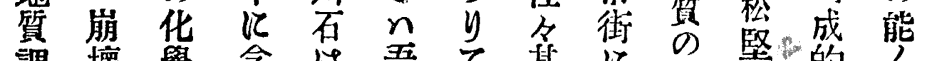

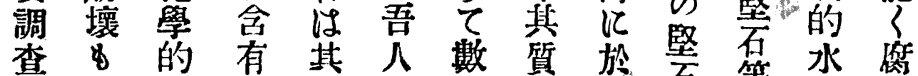

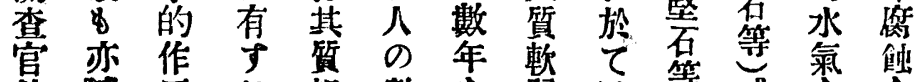

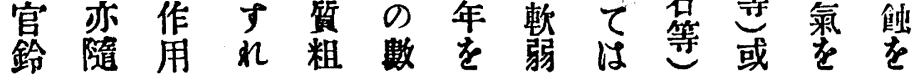

かひに恐 万運運阮 几儥添 寸 减 限 \& 当 其 $n$ r J $丁$ \&䍘謏 數老 保 拾 省 於 萬を 才隨精 の $r I$ 多切孝 y施 江出 L 到 112 \% 步尧後 惯嘍妾 著 檑 需 了及地 
卷 一十第集一第誌 雅 學地

\begin{tabular}{|c|c|c|c|c|c|c|c|c|c|c|c|c|c|c|c|c|c|}
\hline 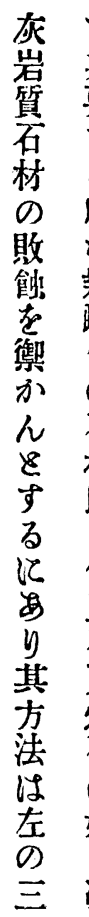 & 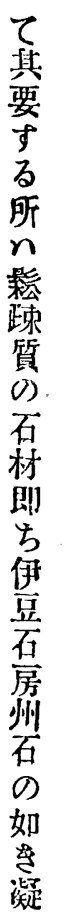 & 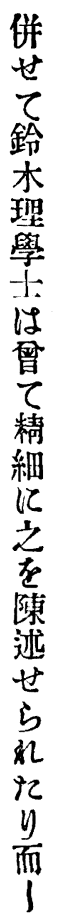 & 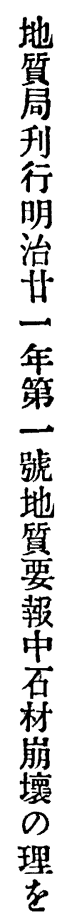 & 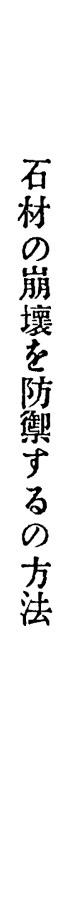 & 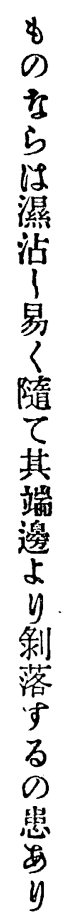 & 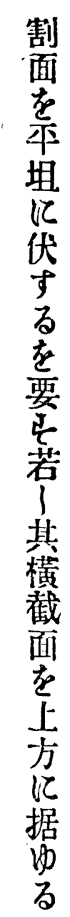 & 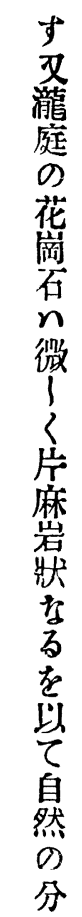 & 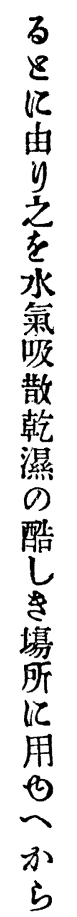 & 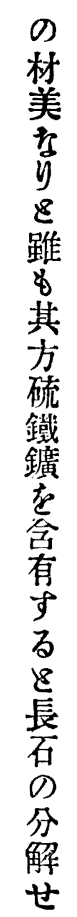 & 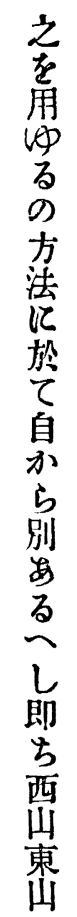 & 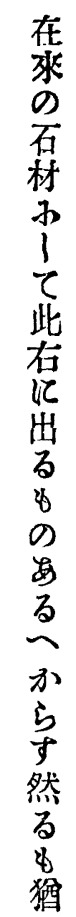 & 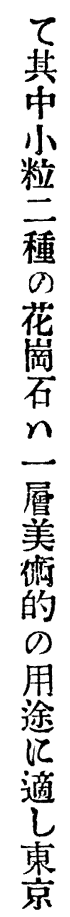 & 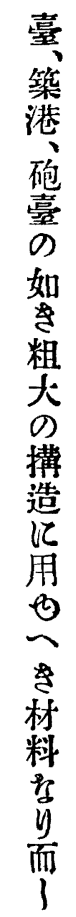 & 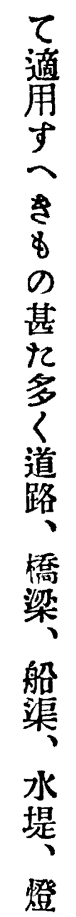 & 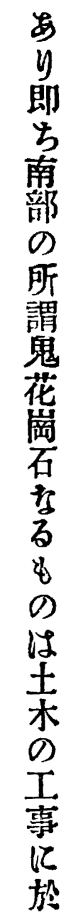 & 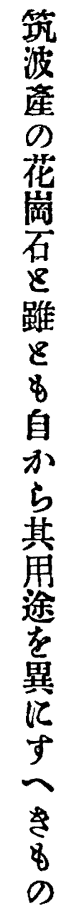 & $\begin{array}{l}\text { 木 } \\
\text { 理 } \\
\text { 學 } \\
\pm \\
\text { さ } \\
\text { 謂 } \\
\text { 説 } \\
\text { を } \\
\text { 引 } \\
\text { 角 } \\
\text { 巳 }\end{array}$ \\
\hline 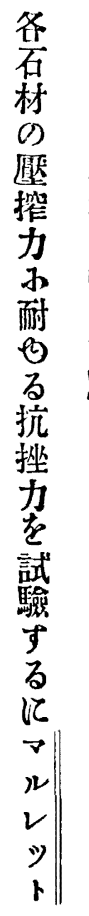 & $\begin{array}{l}\text { 石 } \\
\text { 材 } \\
\text { の } \\
\text { 强 } \\
\text { 嫋 } \\
\text { 試 } \\
\text { 驗 }\end{array}$ & 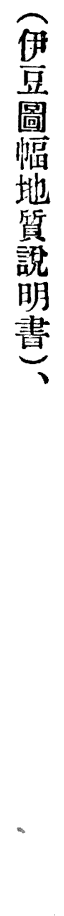 & 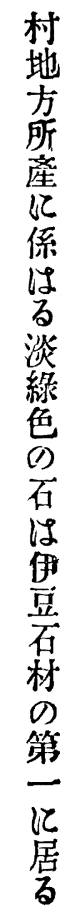 & 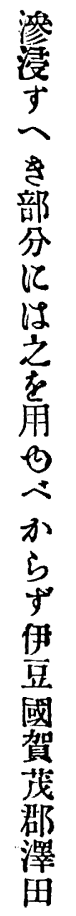 & 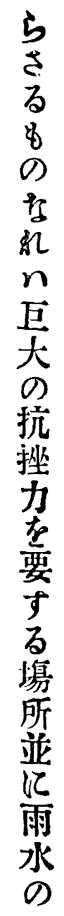 & 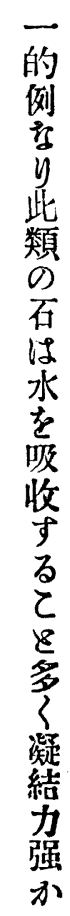 & 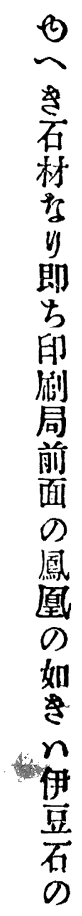 & 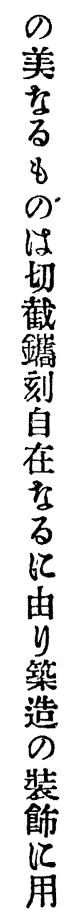 & 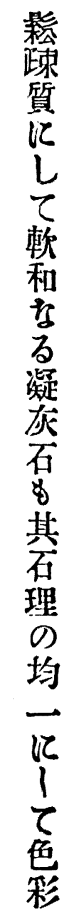 & $\begin{array}{l}\text { 砛 } \\
\text { 贞 } \\
\text { 角 }\end{array}$ & 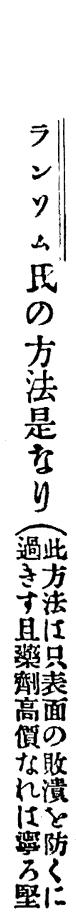 & 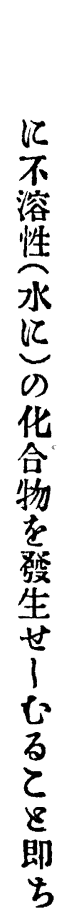 & 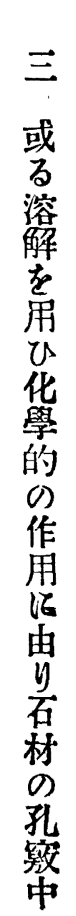 & 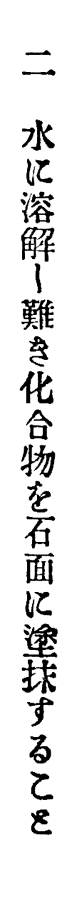 & 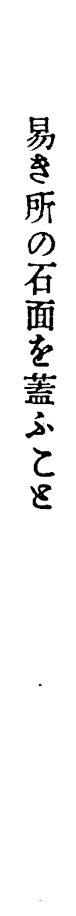 & 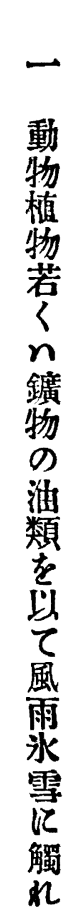 & $\begin{array}{l}\text { 項 } \\
\text { に } \\
\text { 㲻 } \\
3 \\
\text { \& } \\
\text { 云 } \\
\text { s }\end{array}$ \\
\hline
\end{tabular}


兗窈日五十二月一十年二十二治明

\begin{tabular}{|c|c|c|c|c|c|c|c|c|c|c|c|c|c|c|c|c|c|}
\hline 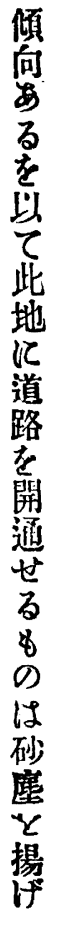 & 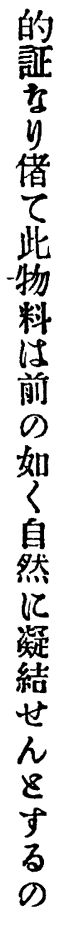 & 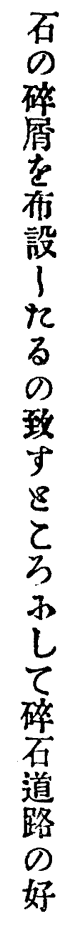 & 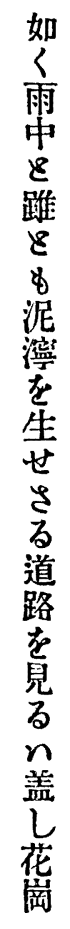 & 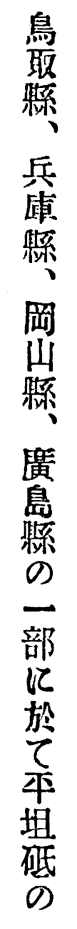 & 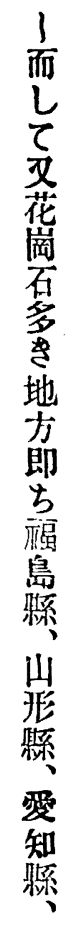 & 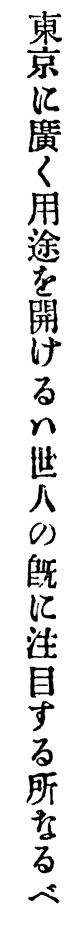 & 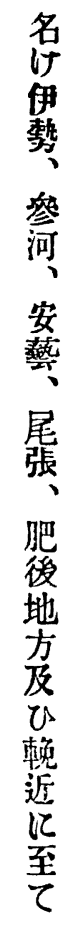 & 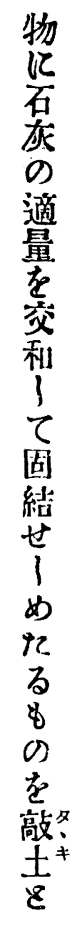 & 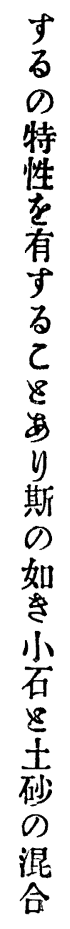 & 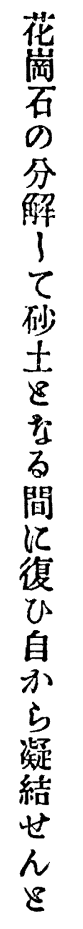 & 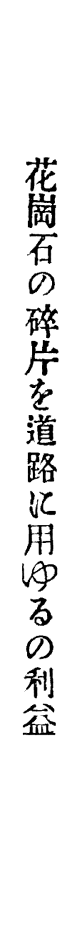 & 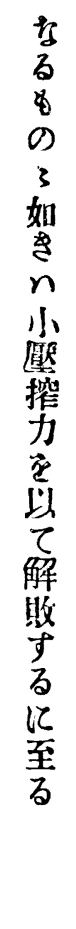 & 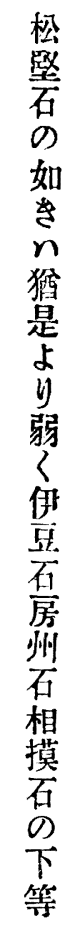 & 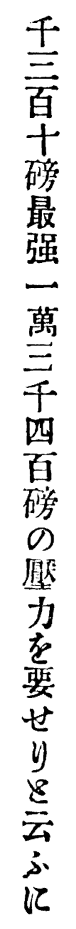 & 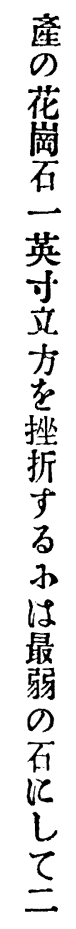 & 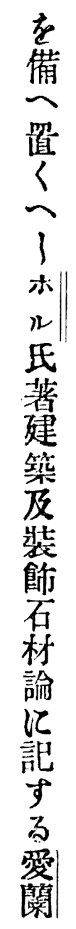 & 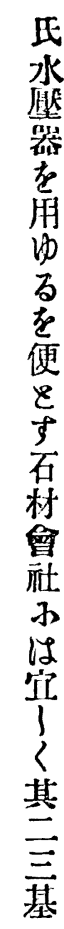 \\
\hline 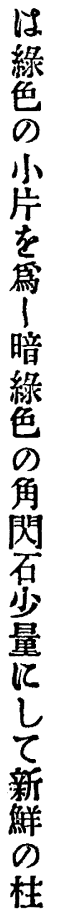 & 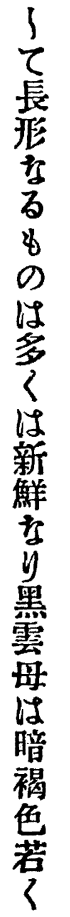 & 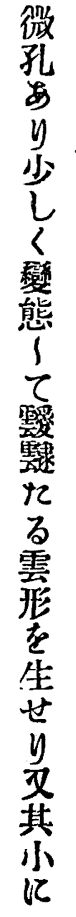 & 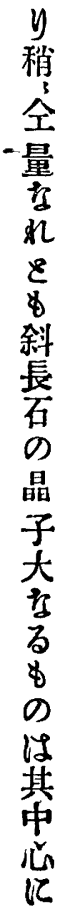 & 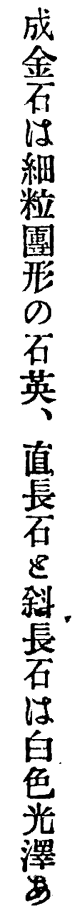 & 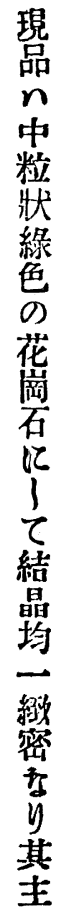 & $\begin{array}{l}\text { 岀 } \\
\text { 角 } \\
\text { 閒 } \\
\text { 花 } \\
\text { 崗 } \\
\text { 岩 }\end{array}$ & 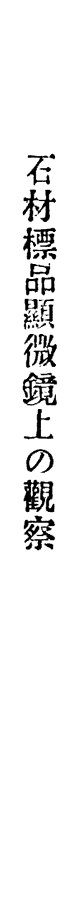 & 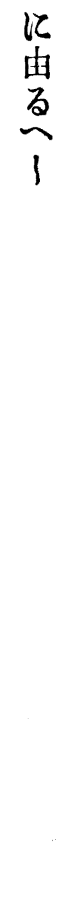 & 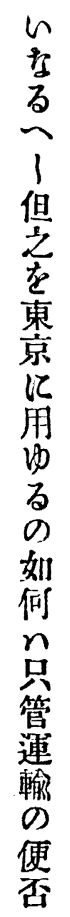 & 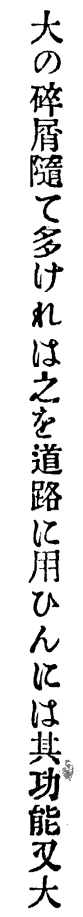 & 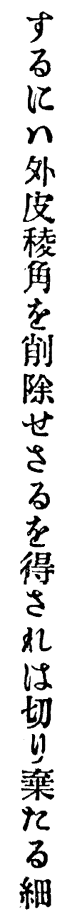 & 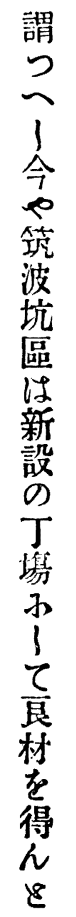 & 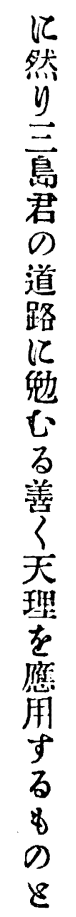 & 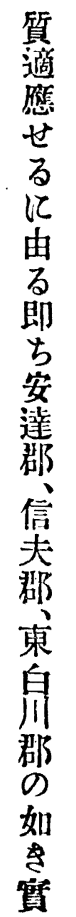 & 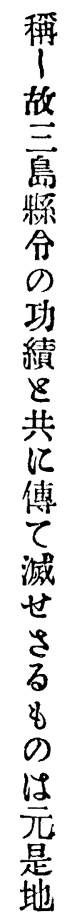 & 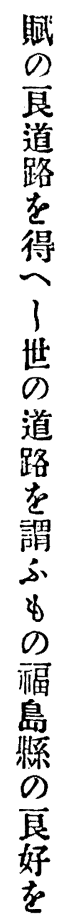 & 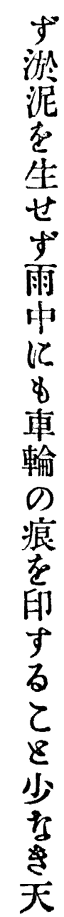 \\
\hline
\end{tabular}




\section{卷 一十第集一第哂雑學地}

\begin{tabular}{|c|c|c|c|c|c|c|c|c|c|c|c|c|c|c|c|c|c|}
\hline 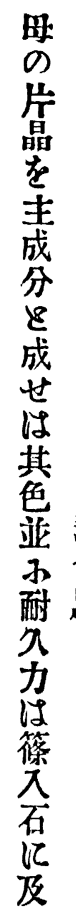 & 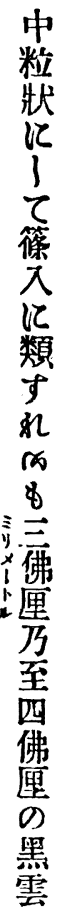 & $\begin{array}{l}\text { 新 } \\
\text { 道 } \\
\text { 坑 }\end{array}$ & 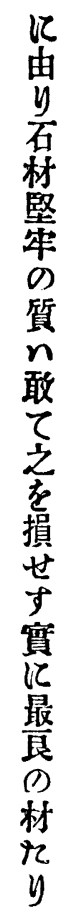 & 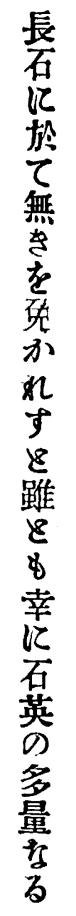 & 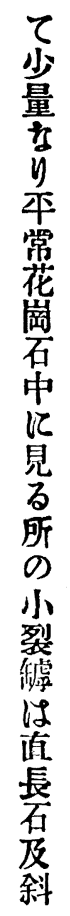 & 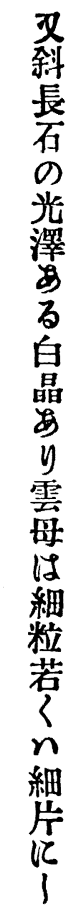 & 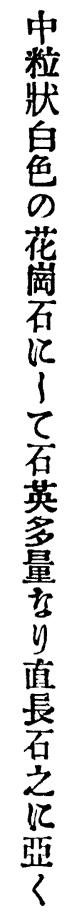 & $\begin{array}{l}\text { 篠 } \\
\text { 坑 }\end{array}$ & 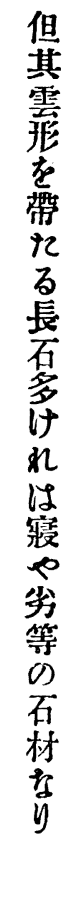 & 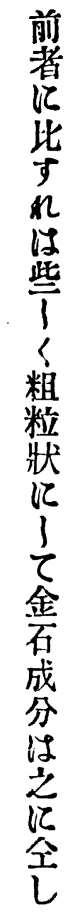 & $\begin{array}{l}\text { 含 } \\
\text { 角 } \\
\text { 閏 } \\
\text { 花 } \\
\text { 崗 } \\
\text { 岩 }\end{array}$ & す & 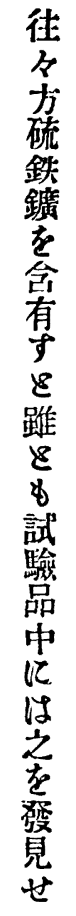 & 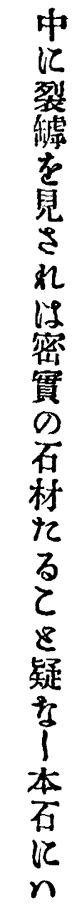 & 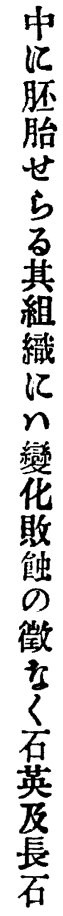 & 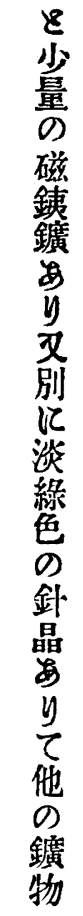 & 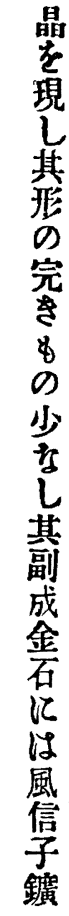 \\
\hline 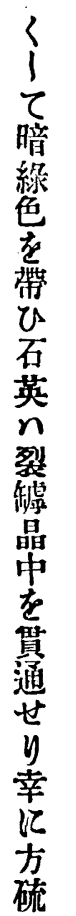 & 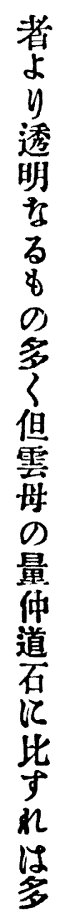 & 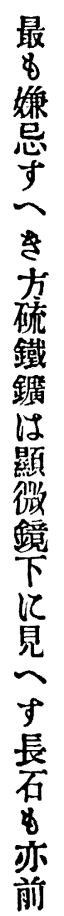 & 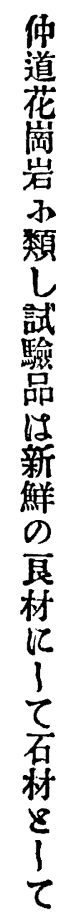 & $\begin{array}{l}\text { 花 } \\
\text { 盛 } \\
\text { 岩 }\end{array}$ & 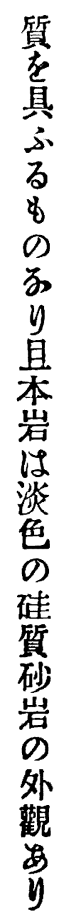 & 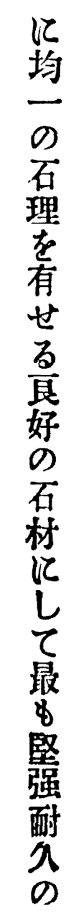 & 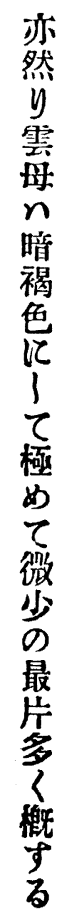 & 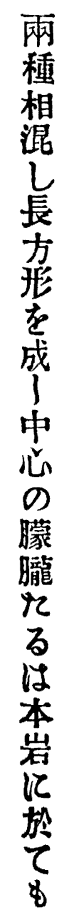 & 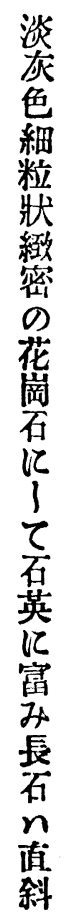 & $\begin{array}{l}\text { 花 } \\
\text { 㞸 }\end{array}$ & 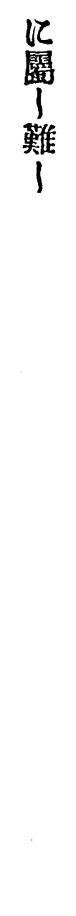 & 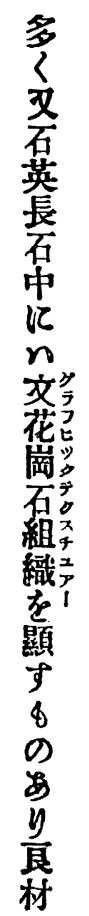 & 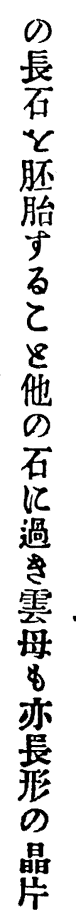 & 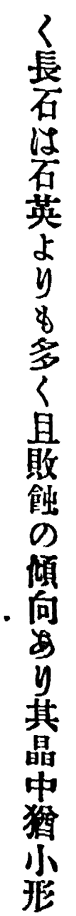 & 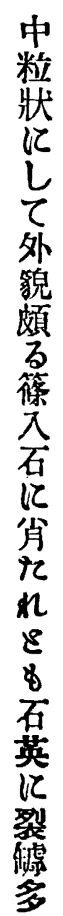 & $\frac{\text { 岩 }}{\frac{\text { 卡 }}{\text { 畤 }}}$ & $\begin{array}{l}\text { ば } \\
\text { ず }\end{array}$ \\
\hline
\end{tabular}


兗發日五十二月一十年”二十二治明

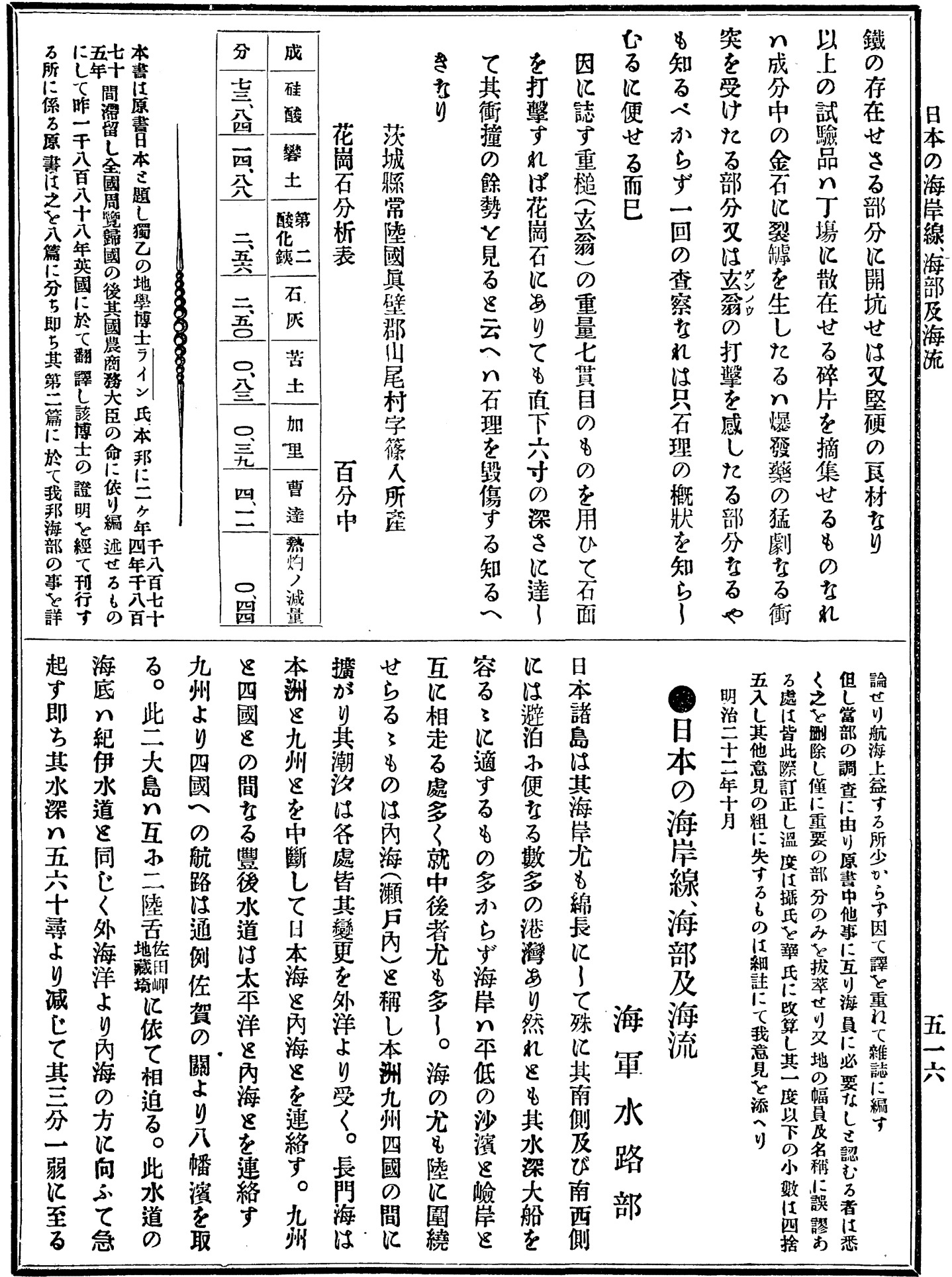

